\title{
R. Kropp Kuriositäten aus dem Deutschen Tuberkulose-Archiv
}

\author{
Curiosities from the German Archive for the History of Tuberculosis
}

Die Beschäftigung mit Zeugnissen früherer Zeiten über die Tuberkulose fördert auch mancherlei Skurriles zutage, das uns zum Schmunzeln, vielleicht zur Häme verführt.

Darüber sollte aber der tragische Hintergrund nicht übersehen werden. Es handelt sich um Äußerungen von Menschen, die der todbringenden Tuberkulose ausgeliefert waren. Diese Dokumente spiegeln ihre Hoffnungslosigkeit, Verzweiflung, auch ihren schwarzen Humor, ihren Sarkasmus. Für uns Heutige, die die damalige Situation kaum kennen und nicht nachempfinden können, haben sie oft einen unfreiwillig komischen Ton.

Das Historische Kaleidoskop bietet Ihnen im Folgenden einen Einblick in diese Welt und in die immer wieder obskuren Heilungs-Angebote jener Zeit.

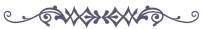

\section{Vorschriften für Hustende}

1. Halte beim Husten stets die flache Hand vor den Mund.

2. Verschlucke den Auswurf nicht.

3. Spucke - außer im Freien - nie auf den Fußboden, sondern immer in eine Spuckschale oder in ein anderes mit ein wenig Wasser gefülltes Gefäß.

Spucke auch nie in das Taschentuch und achte sorgfältig, daß Dein Körper, Deine Wäsche und Kleider nicht mit Auswurf verunreinigt werden.
Dies ist zu Deinem eigenen Schutze nothwendig, damit der Auswurf nicht eintrocknet und zu Staub verwandelt wird, denn die Einathmung eines solchen Staubes ist für Deinen Husten sehr schädlich und läßt ihn nie zur Heilung gelangen.

4. Halte Dich sehr rein und wasche Dir häufig, besonders aber vor jeder Mahlzeit, gründlich die Hände.

5. Küsse niemanden und halte insbesondere Kinder ferne von Dir.

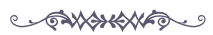

\section{Abendseufzer der Loreley zu Falkenstein}

Ich weiß wohl, was soll es bedeuten,

Dass ich so traurig bin;

Die stecken zu viel mir noch drin.

Die Luft ist zwar gut, aber theuer, Hier oben in Falkenstein; In der Ferne sieht man die Feuer Des Bahnhofs zu Frankfurt am Main.

Ich sitze nun lange schon oben Und füttere Bazillen mit Schleim; Nichts nütztet mein Flehen und Toben; Der Geheimrath läßt mich nicht heim.

Rubrikherausgeber: R. Kropp (federführend), U. Costabel, H. S. Fuchs, C. Habrich, H. Jungbluth, H. J. Klippe, N. Konietzko, R. Loddenkemper, G. Neumann, S. Schulz, M. Teschner 
Zu Hause da sang ich zur Leier

Und hatte Verehrer ne' Schar!

Verschwunden sind jetzt die Freier,

Verblichen mein goldenes Haar!

Ich glaub', um die Gluth mir zu stillen,

Geh auf die Ruin ich allein;

Und stürz mich mitsammt den Bazillen

Von dorten hinab in den Main!

Aus: Neueste Nachrichten aus Schloß Hustenburg,

Fastnacht 1895

(Frei nach Heinrich Heine)

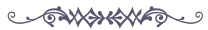

\section{Heirathsgesuch}

Ich bin ein Schwindsuchtkandidat,

Videvidevitbumbum

Der nicht mehr lang zu leben hat,

Videvidevitbumbum

An Jahren jung, an Gütern reich,

Juchheirassa

Mit Haaren schwarz und Wangen bleich,

Juchei.

Ein schönes Mädchen hab ich jetzt

Zu frei'n mir in den Kopf gesetzt,

Derweil es mich gar sehr betrübt,

Einst abzufahren, ungeliebt.

Drum biet' ich Mädchen, jung von Stand,

Schön, brav, gemütvoll, Herz und Hand,

Ersuche unter „Liebeslohn“

Um Brief an die Expedition,

Videvidevit juchhei!

Aus: Davoser Blätter 1895

„Meine Lungenkur mit meinem Lungenstärker, Instrument zur Verhütung und Heilung der Schwindsucht, des Asthmas, Hustens, der Influenza und vieler anderer Krankheiten."

Von Direktor Heinrich Simons, Spezialist für Atmiatrie,

Berlin W. Schöneberg

Verlag A. Bermann, Leipzig o. J. ${ }^{1}$

(Abb.1) Aus diesem Buch werden einige wesentliche Passagen zitiert:

„Allein in Europa sterben jährlich über eine Million Menschen an Schwindsucht, ohne diejenigen, welche jährlich an akuten Er-

\footnotetext{
${ }^{1}$ Das Buch wurde, wie aus dem Inhalt hervorgeht, während der achtziger Jahre des 19. Jahrhunderts verlegt.
}

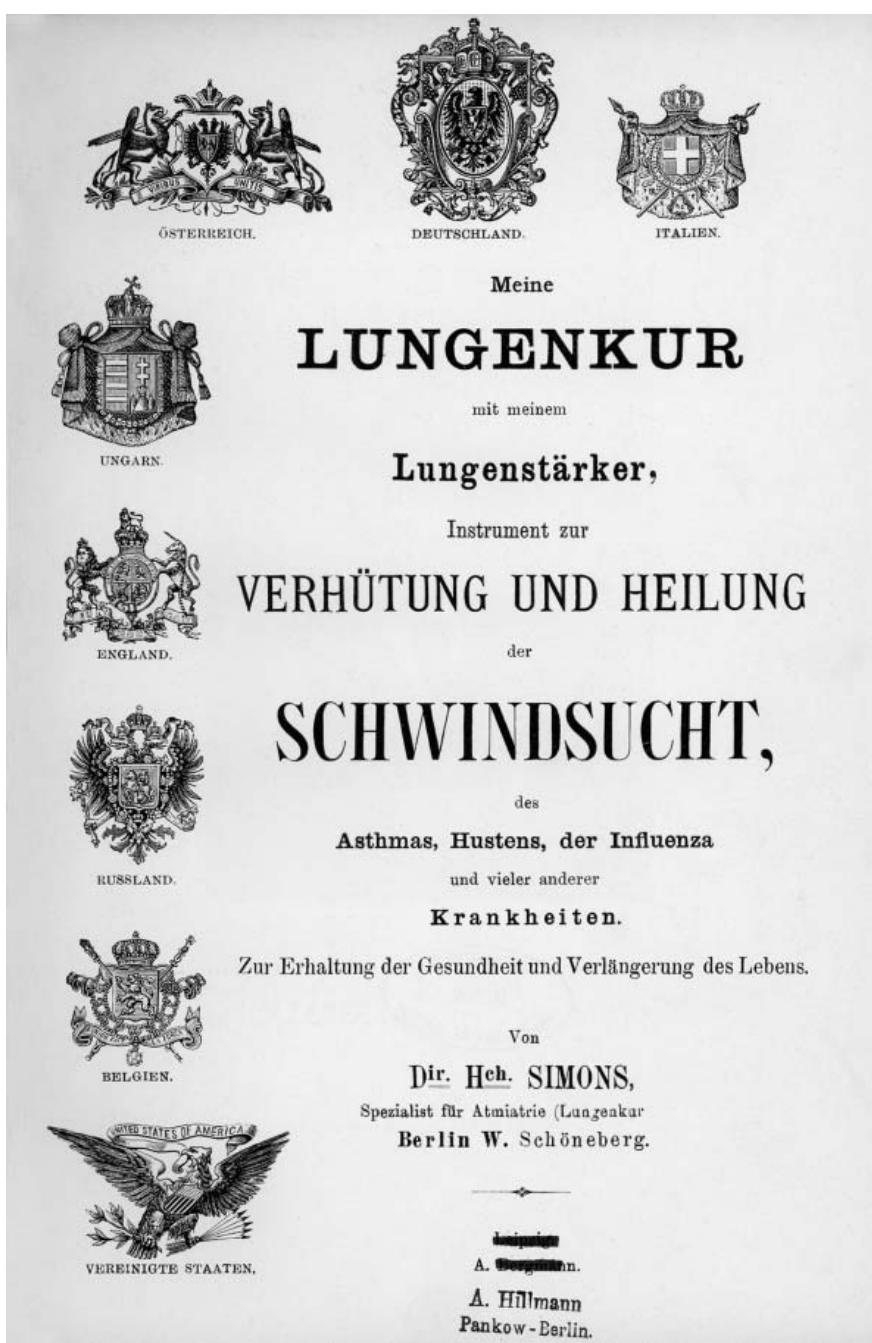

Abb. 1 Titelblatt.

krankungen der Lunge hinscheiden. Im Deutschen Reich sterben jährlich über 160000 Schwindsüchtige. In Paris stirbt der vierte, in New York sogar der dritte Mensch an Lungenschwindsucht oder irgendwelcher Erkrankung der Lunge; so geht es fort und fort. Dieser tückischste und ärgste Feind der Menschheit senkt, gleich einem grausamen Ungeheuer, unablässig seine bedauernswerten Opfer in den kühlen Schooss der Erde und wird sein schreckenerregendes Walten weiterführen, solange die Menschen ihm nicht mit voller Macht und Willenskraft entgegentreten, solange sie selbst es ihm nicht unmöglich machen, noch fernere Verheerungen anzustellen. ...

Gerade unserer Lunge, diesem wichtigsten unserer Lebensorgane, schenken wir die wenigste Aufmerksamkeit, ja wir richten dasselbe oft wissentlich zu Grunde und somit natürlich unsere Gesundheit, unser Leben.

Die Lebens-, Gesellschafts-, Erwerbsverhältnisse zwingen uns, in ungelüfteten, oder allerwenigstens nicht hinreichend gelüfteten Räumen mit allen möglichen, gesunden wie kranken, reinlichen wie unreinlichen Mitmenschen zu verkehren. Im Eisenbahncoupé, im Geschäftslokal, im Gerichtssaal, in Schul- und Versammlungsräumen, im Restaurant, Concertsaal, Theater usw., überall scheiden die Menschen durch Lunge und Haut ihre Unreinheiten aus, alle atmen die gegenseitig verdorbene, wenn nicht verpeste- 
te Luft wieder ein. Was schon durch eine schwindsüchtige Lunge, durch einen mit Flechten-, oder sonstigen Hautausschlag bedeckten Körper ging, das ist man genötigt, einzuatmen, und das sollte nicht krank machen, insbesondere da, wo schon Disposition vorliegt? ...

Bei näherer Untersuchung wird sich als Hauptursache der meisten Krankheiten vorausgegangene mangelhafte Atmung, also Mangel an reiner, frischer Luft herausstellen und als wirksamstes Mittel dagegen wird sich die Steigerung, die Aufbesserung der Atmung, dieser so wichtigen Lebensthätigkeit, erweisen. Die meisten Krankheiten sind Atmungskrankheiten. Warum haben wir denn die Organe Lunge, Herz, Magen, Darm, Leber, Nieren usw. in unserem Körper, warum haben wir das Gehirn, warum die Nerven, die Haut mit ihren Millionen Poren? Jedem ist eine bestimmte Thätigkeit genau vorgeschrieben, jedes arbeitet Hand in Hand mit dem anderen; alle aber entstanden aus Blut, alle können nur durch ununterbrochene Zufuhr von gutem Blut functionieren und fortbestehen, allen wird durch die Atmung, also durch die Lunge, die Essenz der Blutes, der Sauerstoff, zugeführt. Alle dagegen stellen ihre Thätigkeit ein, sobald die Lunge ihren Dienst einstellt. Alle arbeiten mangelhaft, sobald die Lunge mangelhaft arbeitet. Ebenso werden aber auch alle mit vermehrter Tätigkeit arbeiten, sobald die Lunge ihre Thätigkeit vemehrt, alle werden neu belebt und gestärkt, sobald es der Lunge möglich ist, viel reine, frische und sauerstoffreiche Luft zu verarbeiten.“

\section{Gebrauchsanweisung (Abb. 2)}

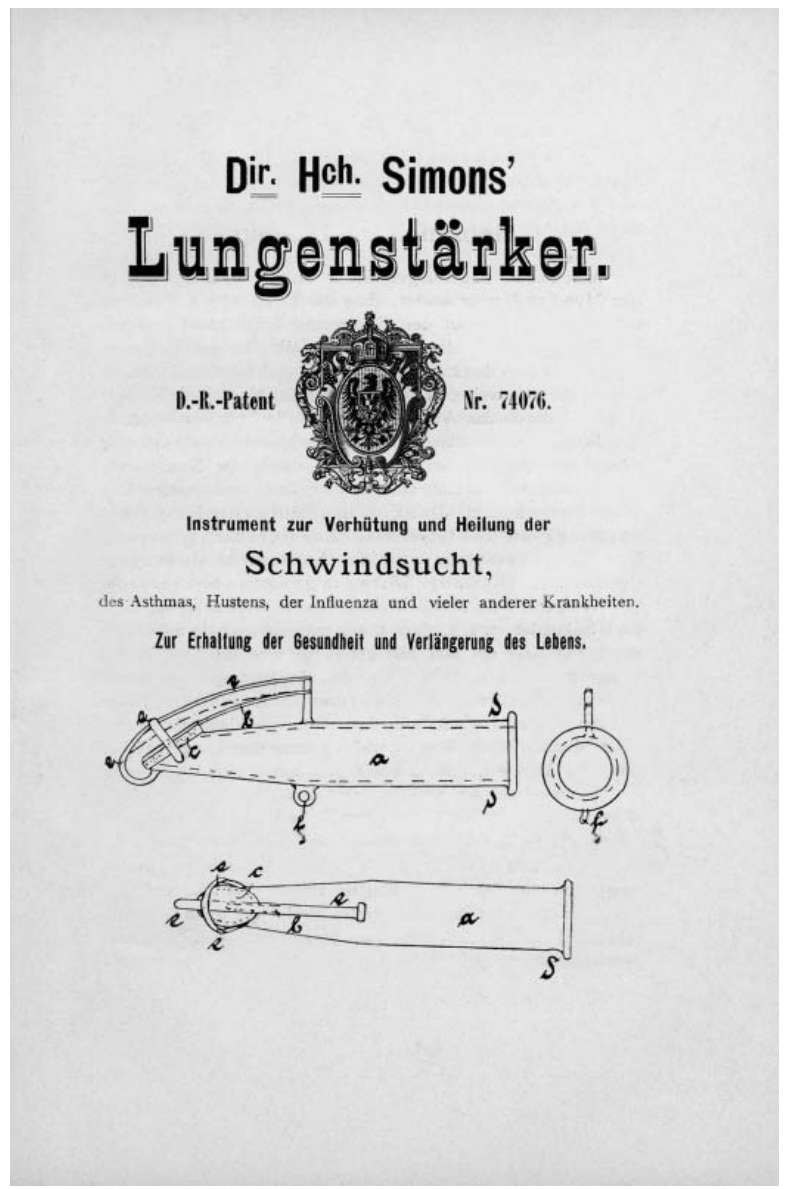

Abb. 2 Atmiatrie (Lungenkur), das ist möglichst vieles und tiefes Einatmen reiner, frischer, wenn auch kalter, sauerstoffreicher Luft.
„Man nehme den Lungenstärker an der offenen Seite in den Mund und zwar soweit, dass die Unterlippe an die Öse und die Oberlippe an den Feder- und Schutzhalter stoßen. Die Klappe kommt also nach oben. Mit den geschlossenen Lippen hält man den Lungenstärker fest und bläst nun langsam, aber nicht stoßweise, in denselben hinein, bis sich die Klappe hebt und durch das Ausströmungsloch die Luft entweicht.

Sobald man nachlässt mit Blasen, schliesst sich die Öffnung wieder und man ist nun gezwungen, durch die Nase einzuatmen; wodurch die Luft staubfrei, erwärmt und angefeuchtet in die Lunge kommt. Das Einatmen durch die Nase muss ganz langsam und leise, also ohne Geräusch in derselben zu verursachen, und durchaus nicht stossweise geschehen. Dies alles bitte ich genau zu beobachten.

Während man ausbläst, zählt man in Gedanken ungefähr nach Sekunden: 1, 2, 3, dann atmet man ebenso viele Sekunden durch die Nase ein und hält genau solange die Luft in der Lunge auf. Es sind demnach drei Ausführungen zu beobachten: 1. Ausblasen, 2. Einatmen, 3. Aufhalten. Diese werden viermal wiederholt, dann tritt eine kleine Pause von 1-2 Minuten ein, während welcher man den Lungenstärker aus dem Munde nimmt und wie gewohnt atmet“.

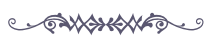

\section{Hygienischer Hosenhalter.}

Gesetzl. geschützt. D.-R.-G. M. Nr. 22808 .

Ein grosser Übelstand besteht auch noch darin, dass wir die bisher gebräuchlichen Hosenträger benutzen. Die Schultern sind ohnedies schon durch das Gewicht der Kleider überlastet, zumal im Winter. Die Hosenträger aber ziehen die Schultern noch mehr herunter, sodass die freie Atmung dadurch sehr behindert wird. hosenhalter und ist es mir bei angestellten Versuchen geradezu unmöglich gewesen, mich durch andere Träger einengen zu lassen. Bei dem Gesundheitshosenhalter, den ich angelegentlich empfehle, ist der Haupthaltepunkt nach den Hüften verlegt, sodass derselbe sich jeder Ausdehnung und $\mathrm{Be}-$ wegung des Körpers anschmiegt; er verleiht dem Körpur ein sondere die Schultern nehmen eine wagerechte Haltung ein, gegenüber der herabhängenden, welche der Gebrauch der bekannten Träger mit sich bringt; abgesehen von der nach vorn gebeugten Haltung, die der Körper mit der Zeit annimmt.

Nach jeder Hüfte schiebe man eine der Platten. Die Häkchen dienen dazu um den Halter an der Hose zu befestigen.

Bei Bestellung Angabe des Leibumfanges erbeten.

Abb. 3 Hygienischer Hosenhalter. 